Revue internationale de l'économie sociale

Recma

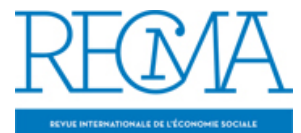

\title{
L'économie sociale européenne est à venir
}

\section{Jean-François Draperi}

Numéro 300, mai 2006

URI : https://id.erudit.org/iderudit/1021788ar

DOI : https://doi.org/10.7202/1021788ar

Aller au sommaire du numéro

Éditeur(s)

Institut de l'économie sociale (IES)

ISSN

1626-1682 (imprimé)

2261-2599 (numérique)

Découvrir la revue

Citer ce document

Draperi, J.-F. (2006). L'économie sociale européenne est à venir. Revue

internationale de l'économie sociale, (300), 4-4.

https://doi.org/10.7202/1021788ar d'utilisation que vous pouvez consulter en ligne.

https://apropos.erudit.org/fr/usagers/politique-dutilisation/ 


\section{L'ÉCONOMIE SOCIALE EUROPÉENNE EST À VENIR}

$\mathrm{P}$

our la seconde année consécutive, la Recma accueille une sélection de contributions aux Rencontres interuniversitaires de l'économie sociale et solidaire. Cette sélection, coordonnée par Danièle Demoustier, offre un regard panoramique et problématisé sur la connaissance et la reconnaissance européenne de l'économie sociale et de ses composantes associatives, coopératives et mutualistes.

La mise en perspective introductive de Danièle Demoustier, en collaboration avec Rafaël Chaves, Magdalena Huncova, Günther Lorenz et Roger Spear, montre que la complexité de la réflexion théorique sur l'économie sociale est redoublée dès lors qu'elle est placée hors des contextes nationaux. Les contributions relatives aux associations - celle de Johan Priou sur les services sociaux, celle de Gilles Caire sur le tourisme social, celle de Laurent Fraisse et de Jeremy Kendall sur le statut d'association européenne - mettent en évidence, chacune dans leur domaine, à la fois la libéralisation des services dans l'Union européenne, comme dans le reste du monde, et les débats qui animent les associations pour faire reconnaître les spécificités de l'économie sociale et aboutir à un statut d'association européenne. Les problèmes rencontrés par les mutuelles et les coopératives sont à la fois comparables et différents: même en l'absence d'un statut européen, les mutuelles sont d'ores et déjà entrées dans une nouvelle ère économique, dont l'adoption du nouveau code est le signe le plus tangible, ainsi que le montre Hélène Vincent; les coopératives, dont l'engagement dans une logique européenne est le plus avancé avec l'adoption du statut de société coopérative européenne, tentent de renforcer leur unité, ainsi qu'en témoigne la création de Cooperatives Europe, présentée par Rainer Schlüter. Ces articles, ainsi que ceux déjà publiés par la Recma, en particulier dans les numéros 291 ( $c f$. le dossier sur la société coopérative européenne) et 295 ( $c f$.l'article de Jean-Claude Detilleux et Caroline Naett sur le projet d'amendement de la norme IAS 32 de l'International Accounting Standards Board sur les instruments financiers), dévoilent une constante: à la fois socialement nécessaire et économiquement combattue, l'économie sociale dérange. Sa légitimité reste toujours à construire. Ses modes d'action, le raisonnement qui les fonde se distinguent assez de ceux des sociétés de capitaux pour qu'ils soient incompris ou combattus par les institutions européennes.

L'économie sociale ne doit donc son salut quà elle-même. Son existence sociale, économique et juridique n'est jamais définitivement acquise, de même qu'elle n'est jamais tout à fait en péril, ne serait-ce que parce que l'économie sociale est capable de se reconstituer sous des formes toujours nouvelles. Dans tous les cas, elle dépend en premier lieu de la capacité collective de ses membres à la faire vivre. 